\title{
Comparison of clinical outcomes between Magmaris and Orsiro drug eluting stent at 12 months: Pooled patient level analysis from BIOSOLVE II-III and BIOFLOW II trials 放
}

\author{
Alexandre Hideo-Kajita ${ }^{\mathrm{a}, 1,2}$, Hector M. Garcia-Garcia ${ }^{\mathrm{a}, *, 1,2}$, Paul Kolm ${ }^{\mathrm{a}, 2}$, Viana Azizi ${ }^{\mathrm{a}, 2}$, Yuichi Ozaki ${ }^{\mathrm{a}, 2}$, \\ Kazuhiro Dan $^{\mathrm{a}, 2}$, Hüseyin Ince ${ }^{\mathrm{b}, \mathrm{c}, 2}$, Stephan Kische ${ }^{\mathrm{d}, 2}$, Alexandre Abizaid ${ }^{\mathrm{e}, 2}$, Ralph Töelg ${ }^{\mathrm{f}, 2}$, \\ Pedro Alves Lemos ${ }^{\mathrm{g}, 2}$, Nicolas M. Van Mieghem ${ }^{\mathrm{h}, 2}$, Stefan Verheye ${ }^{\mathrm{i}, 2}$, Clemens von Birgelen $^{\mathrm{j}, 2}$, \\ Evald Høj Christiansen ${ }^{\mathrm{k}, 2}$, William Wijns ${ }^{1,2}$, Thierry Lefèvre ${ }^{\mathrm{m}, 2}$, Stephan Windecker ${ }^{\mathrm{n}, 2}$, Ron Waksman ${ }^{\mathrm{a}, 2}$, \\ Michael Haude ${ }^{0,2}$, on behalf of theBIOFLOW-II, BIOSOLVE-II and BIOSOLVE-III investigators
}

\footnotetext{
a Division of Interventional Cardiology - MedStar Cardiovascular Research Network, MedStar Washington Hospital Center, USA

b Department of Cardiology, Vivantes Klinikum im Friedrichshain and Vivantes Klinikum Am Urban, Berlin, Germany

c Department of Cardiology, Universitätsmedizin Rostock, Rostock, Germany

d Department of Cardiology, Vivantes Klinikum im Friedrichshain, Berlin, Germany

e Instituto Dante Pazzanese de Cardiologia, São Paulo, Brazil

${ }^{\mathrm{f}}$ Herzzentrum Segeberger Kliniken, Henstedt-Ulzburg, Germany

${ }^{g}$ Instituto do Coração - HCFMUSP, Universidade de São Paulo, São Paulo, Brazil

h Thoraxcenter, Erasmus Medical Center, Rotterdam, the Netherlands

i Interventional Cardiology, Middelheim Hospital, Antwerp, Belgium

j Medisch Spectrum Twente, Thoraxcentrum Twente, Enschede, the Netherlands

${ }^{\mathrm{k}}$ Aarhus University Hospital, Skejby, Aarhus, Denmark

${ }^{1}$ Cardiovascular Research Center Aalst, OLV Hospital, Aalst, Belgium

${ }^{\mathrm{m}}$ Institut Cardiovasculaire Paris Sud (ICPS), Massy, France

n Department of Cardiology, Bern University Hospital, Bern, Switzerland

${ }^{\circ}$ Lukaskrankenhaus Neuss, Neuss, Germany
}

\section{A R T I C L E I N F O}

\section{Article history:}

Received 16 July 2019

Received in revised form 30 August 2019

Accepted 4 November 2019

Available online $\mathrm{xxxx}$

\section{Keywords:}

Magmaris

Orsiro

Target lesion failure

Multivariate analysis

12 months follow-up

\begin{abstract}
A B S T R A C T
Background: The aim of this study was to compare the 12-month clinical outcomes of patients treated with Magmaris or Orsiro. Second generation drug-eluting absorbable metal scaffold Magmaris (Dreams 2G) has proved to be safe and effective in the BIOSOLVE-II study. Similarly, biodegradable polymer sirolimus-eluting stent, Orsiro has shown notable clinical results even in all-comer populations.

Methods: Magmaris group patients were taken from the BIOSOLVE-II and BIOSOLVE-III trials, while the patients from Orsiro group were enrolled in BIOFLOW-II trial. The primary outcome was explored using a time-to-event assessment of the unadjusted clinical outcomes for target lesion failure (TLF) at 12 months, followed by a multivariate analysis adjusting for all the significantly different covariates between the groups.

Results: The study population consisted of 482 patients (521 lesions), 184 patients (189 lesions) in Magmaris group and 298 patients (332 lesions) in Orsiro group. The mean age was $65.5 \pm 10.8$ and $62.7 \pm 10.4$ years in Magmaris and Orsiro groups, respectively $(p=0.005)$. Magmaris and Orsiro unadjusted TLF rates were 6.0 and $6.4 \%$ with no significant difference between the groups $(p=0.869)$. In the multivariate analysis, there were no meaningful differences between Magmaris and Orsiro groups. Finally, none of the groups presented device thrombosis cases at 12 months.

Conclusion: At 12 months there were no significant differences between Magmaris and Orsiro groups neither in the unadjusted assessment nor in the multivariate analysis for target lesion failure. These results should be taken as hypothesis generating and may warrant a head to head comparison on a randomized fashion.
\end{abstract}

(c) 2019 Published by Elsevier B.V.

is No grant support.

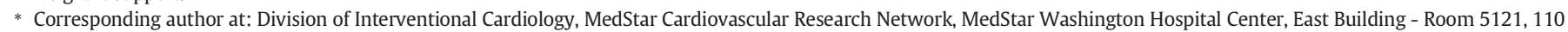
Irving St NW, 20010 Washington, DC, USA.

E-mail address: hector.m.garciagarcia@medstar.net (H.M. Garcia-Garcia).

1 These authors contributed equally.

${ }^{2}$ This author takes responsibility for all aspects of the reliability and freedom from bias of the data presented and their discussed interpretation. 


\section{Background}

Percutaneous coronary interventions with metallic drug-eluting stents (DES) have proven to be safe and effective in most clinical scenarios [1]. The adoption of these devices, however, aroused other issues such as stent thrombosis (ST) [2]. The bioresorbable scaffold (BRS) concept fostered the idea that these matters would be minimized [3]. However, this promise has not been fulfilled by the first-generation polymeric BRS since they have been associated with an increased rate of ST at all-time points compared to metallic DES [4,5]. Subsequently, newer metallic BRS platforms such as the second-generation drugeluting Resorbable Magnesium Scaffold (RMS), Magmaris (Dreams $2 \mathrm{G}$ ), have been introduced, and short- to mid-term results are promising [6,7]. Magmaris has proved to be safe and effective in the BIOSOLVE-II trial and in the long-term follow-up [7]. Likewise, the ultrathin, biodegradable polymer sirolimus-eluting stent (Orsiro) has shown good clinical results in all-comer populations $[9,10]$. There has not yet been a comparison between this second-generation RMS and a metallic DES. The aim of this study is to compare the 12-month clinical outcomes of patients treated with Magmaris or Orsiro.

\section{Methods}

\subsection{Study design and population}

The patients included in the analysis were taken from BIOSOLVE-II, BIOSOLVE-III, and BIOFLOW-II trials. The Magmaris group was composed of the patients from 2 Magmaris registries (BIOSOLVE-II and BIOSOLVE-III trials) [6,7], while the Orsiro group was composed of the patients from 1 Orsiro randomized control trial (RCT) (BIOFLOW-II trial) [9]. The study designs for these trials have been previously published elsewhere [6-9]. The inclusion criteria were similar (otherwise indicated): [1] stable or unstable angina, documented silent ischemia (BIOFLOW II also included patients with clinically driven myocardial infarction (CDMI)); [2] Lesion length was $\leq 26 \mathrm{~mm}$ for BIOFLOW-II and $\leq 21 \mathrm{~mm}$ for BIOSOLVE-II and BIOSOLVE-III; and [3] Reference target vessel diameter $\geq 2.25$ to $4.0 \mathrm{~mm}, \geq 2.2$ to $3.8 \mathrm{~mm}$, and $\geq 2.7$ to $3.8 \mathrm{~mm}$ for BIOFLOW-II, BIOSOLVE-II, and BISOLVE-III, respectively. The exclusion criteria were [1] left ventricle ejection fraction $\leq 30 \%$; [2] presence of thrombus in the target vessel (TV); [3] TV with severe calcification; [4] Target Lesion (TL) is a bifurcation lesion involving a side branch $>2.0 \mathrm{~mm}$ in diameter; [5] three-vessel coronary artery disease (CAD) at time of the index procedure; [6] TL is located in or supplied by an arterial or venous bypass graft; [7] unprotected left main coronary artery disease; [8] $\mathrm{MI} \leq 72 \mathrm{~h}$ before the index procedure; and [9] ostial target lesions in BIOSOLVE-II and BIOSOLVE-III. The lists of all inclusion and exclusion criteria for the 3 studies are available at ClinicalTrials.gov (NCT01356888, NCT01960504, and NCT02716220 for BIOFLOW-II, BIOSOLVE-II, and BIOSOLVE-III, respectively).

\subsection{Devices in the study}

The specifications and details of each device in this study (i.e. Magmaris, Orsiro, and Xience) were previously described [6-9].

\subsection{Procedure and medications}

In the BIOFLOW-II trial, the patients were allocated in the Orsiro or Xience groups. Pre-dilation was recommended but not mandatory. The use of $>1$ study device per TL was limited to bailout situations. In BIOSOLVE-II and -III, pre-dilation was mandatory before Magmaris deployment; post-dilation was not (but advised). The use of $>1$ scaffold per TL was also limited to bailout situations. In case of study device failure, in BIOSOLVE-II and -III trials, an Orsiro stent was used.

The concomitant medications in all studies were unfractionated heparin or low-molecular-weight heparin during the index procedure following the centers' practice. The antiplatelet regimen was acetylsalicylic acid (ASA) $\geq 3$ days before the procedure dose of $75-100 \mathrm{mg}$ (pre-procedure loading dose of $250-500 \mathrm{mg}$ ) and clopidogrel loading dose of 300-600 $\mathrm{mg} 6 \mathrm{~h}$ before index procedure (except for those already in use of $75 \mathrm{mg} /$ day for $\geq 7$ days). Dual antiplatelet therapy (DAPT) regimen was given to all patients for at least 6 months after device implantation.

\subsection{Outcomes and definitions}

Target lesion failure (TLF) at 12 months was the primary outcome. TLF was defined as a composite of cardiac death, target vessel myocardial infarction (TVMI), and clinically driven target lesion revascularization (CD-TLR) in the BIOFLOW-II and BIOSOLVE-II and -III trials [6-9].

The secondary outcomes included the individual components of the primary outcome plus death, any myocardial infarction (MI), any target lesion revascularization (TLR), any target vessel revascularization (TVR), clinically driven TVR (CD-TVR), target vessel failure (TVF), and ST for each group. TVF was defined as the composite of cardiac death, target-vessel MI, and CD-TVR.

Previously, MI was defined following the Society for Cardiovascular Angiography and Interventions (SCAI) consensus in the BIOSOLVE-II and -III trials. In BIOFLOW-II trial, the Third Universal Definition of MI and Academic Research Consortium (ARC) guidelines definitions were used [11-13]. The present analysis defined MI in consonance to the Third Universal Definition of MI, since the variable that was also available in BIOSOLVE-II and -III the patient level data [12].

TLR, TVR and ST were defined in accordance with ARC guidelines in BIOFLOW-II, BIOSOLVE-II and -III trials [11].

\subsection{Statistical analysis}

Means and standard deviations were used to present continuous variables, and frequencies and percentages for categorical variables in the following tables. Baseline characteristics, procedure characteristics, and the unadjusted clinical outcomes differences between the Magmaris and Orsiro groups were compared with standardized differences expressed in $p$-values. The $p$-value was considered statistically significant when $p<0.05$, otherwise indicated. The unadjusted clinical outcomes time-to-event assessment for TLF was modeled as a mixed effects Weibull survival distribution, incorporating different sites within the same country as random effects [14,15]. Kaplan-Meier curves were constructed for the unadjusted survival functions of the Magmaris vs. Orsiro devices. The statistical analysis was performed using Stata v.15 (Stata Corp, College Station, TX, USA).

\subsection{Multivariate analysis}

The multivariate analysis (MVA) for the primary outcome was performed in 2 steps. TLF was set as the main outcome variable (dependent). The first step included all the significantly different covariates between the Magmaris and Orsiro groups in the unadjusted data taken from the baseline and procedure characteristics. The variables included in the MVA were: Orsiro stent, age, male gender, history of smoking (previous and current), diabetes mellitus (with and without insulin-therapy) unstable angina, ACC/AHA lesion characterization (Types A, B1, B2 and C), pre- and post-procedure percentage of diameter stenosis (\%DS). The second step evaluated the interactions of the Orsiro stent with all the covariates included in the 1st step. In order to control Type I error rate, the statistical significance for the covariates interactions was set at 0.01 . 


\section{Results}

\subsection{Study population}

The study population consisted of 482 patients (521 lesions). In the Magmaris group, there were 184 patients (189 lesions), and in the Orsiro group, there were 298 patients (332 lesions) (Fig. 1). The baseline characteristics are listed in Table 1 . The Magmaris group's mean age was $65.5 \pm 10.8$ years, and in the Orsiro group, the mean age was $62.7 \pm 10.4$ years $(p$-value $=0.005)$. Male gender was $63.6 \%$ and $78.2 \%$ in Magmaris and Orsiro groups $(p<0.001)$, respectively. Unstable angina was $12.5 \%$ in Magmaris group compared to $19.5 \%$ in Orsiro group ( $p=0.047)$. Previous smokers were $16.3 \%$ in Magmaris group vs. $30.0 \%$ in Orsiro group $(p<0.001)$. Lesion classification by the American College of Cardiology/American Heart Association (ACC/AHA) type A was $41.8 \%$ in Magmaris group vs. $26.4 \%$ in Orsiro group $(p<0.001)$, and Type $C$ lesions were $4.2 \%$ vs. $14.2 \%(p<0.001)$ in the Magmaris and Orsiro groups, respectively. A summary of procedure characteristics is also presented in Table 1. Up to 6 months, all patients in both groups were taking dual anti-platelet therapy (DAPT), while $>6$ months $58.7 \%$ of the Magmaris group and $96.3 \%$ of the patients in Orsiro group were receiving DAPT $(p<0.001)$. Lesion length was $12.4 \pm 5.0 \mathrm{~mm}$ in the Magmaris group and $13.3 \pm 6.7 \mathrm{~mm}$ in the Orsiro group $(p=0.117)$. The reference vessel diameter (RVD) was $2.7 \pm 0.4 \mathrm{~mm}$ and $2.8 \pm 0.5 \mathrm{~mm}$ in the Magmaris and Orsiro groups ( $p=0.169$ ), respectively. Pre-procedure \%DS was $54.8 \pm 11.8 \%$ in the Magmaris group compared to $66.7 \pm$ $14.3 \%$ in the Orsiro group ( $p<0.001)$. Post-procedure \%DS (in-segment) was $19.6 \pm 7.6 \%$ in the Magmaris group compared to $15.8 \pm 6.8 \%$ in the Orsiro group $(p<0.001)$.

\subsection{Unadjusted Magmaris versus Orsiro clinical outcomes comparison}

The unadjusted clinical outcomes of the Magmaris and Orsiro groups at 12 months are listed in Supplemental Table 1. The primary comparison, which is TLF, revealed to be not significant between the groups, $6.0 \%$ in the Magmaris group vs. $6.4 \%$ in the Orsiro group ( $p=0.869$ ), as presented in Fig. 2. In the secondary outcomes, neither the individual components of the TLF nor the other clinical outcomes showed statistically significant differences between the Magmaris or Orsiro groups for cardiac death $(p=0.640)$, target vessel MI $(p=0.783)$, CD-TLR $(p=$ $0.268)$, death $(p=0.387)$, MI $(p=0.459)$, any TLR $(p=0.265)$, any

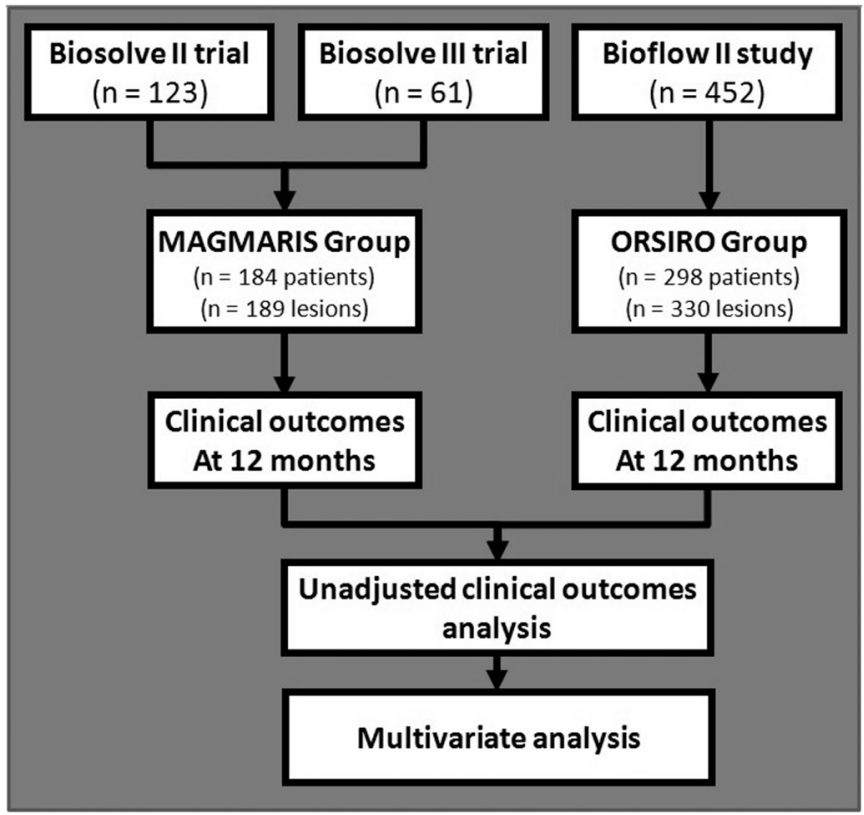

Fig. 1. Flow diagram of the study.
Table 1

Baseline and procedure characteristics of the patients treated with Magmaris or Orsiro.

\begin{tabular}{|c|c|c|c|c|c|}
\hline & \multicolumn{2}{|c|}{$\begin{array}{l}\text { Magmaris group, } \\
\text { ITT }\end{array}$} & \multicolumn{2}{|c|}{ Orsiro group, ITT } & \multirow[t]{2}{*}{$p$-Value } \\
\hline & $\mathrm{N}($ total $)$ & $\%$ & $\mathrm{~N}($ total $)$ & $\%$ & \\
\hline \multicolumn{6}{|l|}{ Baseline characteristics } \\
\hline Age, years (mean $\pm S D$ ) & 65.5 & \pm 10.8 & 62.7 & \pm 10.4 & 0.005 \\
\hline Male gender & $\begin{array}{l}117 \\
(184)\end{array}$ & 63.6 & $\begin{array}{l}233 \\
(298)\end{array}$ & 78.2 & $<0.001$ \\
\hline \multicolumn{6}{|l|}{ Risk factors } \\
\hline Hypertension & $\begin{array}{l}146 \\
(184)\end{array}$ & 79.4 & $\begin{array}{l}231 \\
(298)\end{array}$ & 77.8 & 0.636 \\
\hline Hypercholesterolemia & $\begin{array}{l}114 \\
(184)\end{array}$ & 62.0 & $\begin{array}{l}202 \\
(289)\end{array}$ & 69.9 & 0.074 \\
\hline History of MI & $42(184)$ & 22.8 & $89(290)$ & 30.7 & 0.062 \\
\hline $\begin{array}{l}\text { Previous coronary } \\
\text { intervention }^{\mathrm{a}}\end{array}$ & $76(184)$ & 41.3 & $\begin{array}{l}128 \\
(298)\end{array}$ & 42.9 & 0.722 \\
\hline \multicolumn{6}{|l|}{ Diabetes mellitus } \\
\hline Non-diabetic & $\begin{array}{l}138 \\
(184)\end{array}$ & 75.0 & $\begin{array}{l}206 \\
(290)\end{array}$ & 71.0 & 0.346 \\
\hline Non-insulin dependent & $34(184)$ & 18.5 & $66(290)$ & 22.8 & 0.266 \\
\hline Insulin-dependent & $12(184)$ & 6.5 & $18(290)$ & 6.2 & 0.891 \\
\hline \multicolumn{6}{|l|}{ History of smoking } \\
\hline Non-smoker & $82(184)$ & 44.6 & $92(290)$ & 31.7 & 0.005 \\
\hline Previous smoker & $30(184)$ & 16.3 & $87(290)$ & 30.0 & $<0.001$ \\
\hline Current smoker & $72(184)$ & 39.1 & $\begin{array}{l}111 \\
(290)\end{array}$ & 38.3 & 0.852 \\
\hline \multicolumn{6}{|l|}{$\begin{array}{l}\text { Dual anti-platelet therapy } \\
\text { duration }\end{array}$} \\
\hline$\leq 6$ months & $\begin{array}{l}184 \\
(184)\end{array}$ & 100.0 & $\begin{array}{l}296 \\
(296)\end{array}$ & 100.0 & - \\
\hline$>6$ months & $\begin{array}{l}108 \\
(184)\end{array}$ & 58.7 & $\begin{array}{l}285 \\
(296)\end{array}$ & 96.3 & $<0.001$ \\
\hline \multicolumn{6}{|l|}{ Ischemic status } \\
\hline Unstable angina & $23(184)$ & 12.5 & $58(298)$ & 19.5 & 0.047 \\
\hline True bifurcation lesions ${ }^{\mathrm{b}}$ & $5(189)$ & 2.6 & $4(330)$ & 1.2 & 0.229 \\
\hline \multicolumn{6}{|l|}{ Target vessel } \\
\hline LMCA & $0(189)$ & 0.0 & $0(330)$ & 0.0 & - \\
\hline LAD & $78(189)$ & 41.3 & $\begin{array}{l}148 \\
(330)\end{array}$ & 44.8 & 0.429 \\
\hline $\mathrm{LCX}$ & 47(189) & 24.9 & $73(330)$ & 22.1 & 0.475 \\
\hline RCA & 64(189) & 33.9 & $\begin{array}{l}109 \\
(330)\end{array}$ & 33.0 & 0.847 \\
\hline \multicolumn{6}{|l|}{ ACC/AHA lesion characterization } \\
\hline Type A & 79(189) & 41.8 & $87(330)$ & 26.4 & $<0.001$ \\
\hline Type B1 & $74(189)$ & 39.2 & $\begin{array}{l}150 \\
(330)\end{array}$ & 45.4 & 0.163 \\
\hline Type B2 & 28(189) & 14.8 & $46(330)$ & 13.9 & 0.784 \\
\hline Type C & $8(189)$ & 4.2 & $47(330)$ & 14.2 & $<0.001$ \\
\hline \multicolumn{6}{|l|}{ Procedure characteristics } \\
\hline Lesion length, $\mathrm{mm}$ (mean $\pm \mathrm{SD}$ ) & 12.4 & \pm 5.0 & 13.3 & \pm 6.7 & 0.117 \\
\hline $\mathrm{RVD}, \mathrm{mm}($ mean $\pm \mathrm{SD})$ & 2.7 & \pm 0.4 & 2.8 & \pm 0.5 & 0.169 \\
\hline Pre-procedure \%DS $(\% \pm \mathrm{SD})$ & 54.8 & \pm 11.8 & 66.7 & \pm 14.3 & $<0.001$ \\
\hline Post-procedure $\% \mathrm{DS}(\% \pm \mathrm{SD})$ & 19.6 & \pm 7.6 & 15.8 & \pm 6.8 & $<0.001$ \\
\hline
\end{tabular}

Abbreviations: \%DS = percentage of diameter stenosis; $\mathrm{ACC}=$ American College of cardiology; $\mathrm{AHA}=$ American Heart Association; $\mathrm{CABG}=$ coronary artery bypass grafting; ITT $=$ intention to treat; LMCA = left main coronary artery; LAD = left anterior descending artery; $\mathrm{LCX}=$ left circumflex artery; $\mathrm{MI}=$ myocardial intervention; $\mathrm{PCI}=$ percutaneous coronary intervention; RCA = right coronary artery; RVD = reference vessel diameter; $\mathrm{SD}=$ standard deviation.

a $\mathrm{PCI}$ or $\mathrm{CABG}$.

b True bifurcations were defined as Medina Classification 1.1.1, 0.1.1 and 1.0.1.

TVR $(p=0.903)$, CD-TVR $(p=0.153)$, and TVF ( $p=0.549)$. Of note, there were no definite or probable ST cases in the Magmaris or Orsiro groups.

\subsection{Multivariate analysis}

The covariates included in the first and second steps of the MVA were age, male gender, diabetes, smoking status, unstable angina, ACC/AHA lesion classification (types A, B1, B2 and C), pre- and postprocedure percentage of diameter stenosis (\%DS) assessed by Quantitative Coronary Angiography (QCA), and device type (i.e. Orsiro stent). In 


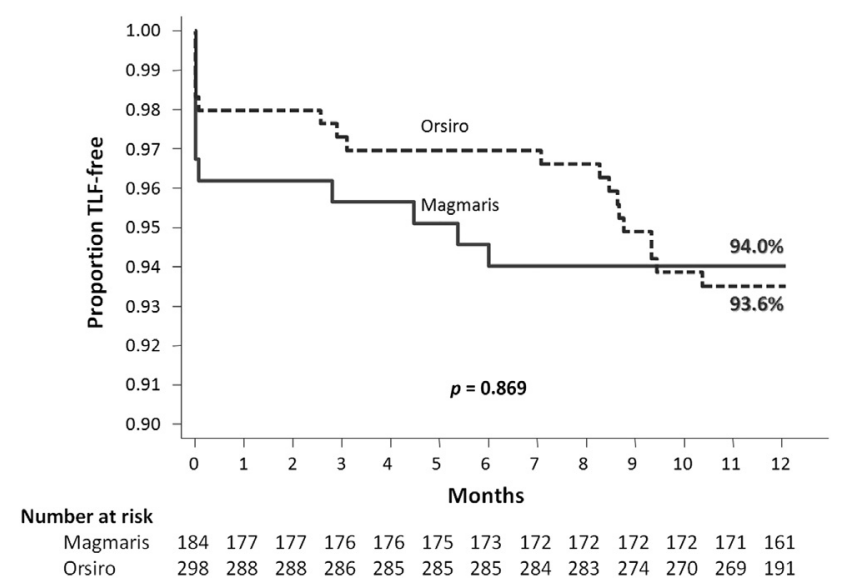

Fig. 2. Kaplan-Meier survival estimates free of target lesion failure.

Table 2, the MVA results are presented. After the adjustment of all covariates, there were no meaningful differences between the Magmaris and Orsiro groups for the first and second steps (i.e. covariates and covariates interactions, respectively) of the multivariate analysis, albeit the Orsiro stent revealed a TLF reduction of $24 \%$ in hazard function ( $p$ $=0.533$ ).

\section{Discussion}

This is the first report comparing the clinical outcomes between an absorbable metal scaffold, like Magmaris, and Orsiro after 12 months. There are 2 main findings from our analysis: [1] at 12 months, the

Table 2

Magmaris vs. Orsiro covariate multivariate analysis and interactions.

\begin{tabular}{|c|c|c|c|}
\hline & $\begin{array}{l}\text { Hazard } \\
\text { ratio }\end{array}$ & $\begin{array}{l}95 \% \\
\text { confidence } \\
\text { interval }\end{array}$ & $p$-Value \\
\hline \multicolumn{4}{|l|}{ Covariates comparison } \\
\hline Orsiro stent & 0.76 & $0.31-1.87$ & 0.533 \\
\hline Age & 0.99 & $0.95-1.03$ & 0.662 \\
\hline Male gender & 0.79 & $0.31-2.03$ & 0.629 \\
\hline \multicolumn{4}{|l|}{ History of smoking } \\
\hline Previous & 1.45 & $0.55-3.83$ & 0.453 \\
\hline Current & 2.01 & $0.70-5.75$ & 0.193 \\
\hline \multicolumn{4}{|l|}{ Diabetes mellitus } \\
\hline Insulin & 1.10 & $0.25-4.82$ & 0.995 \\
\hline Non-insulin & 1.19 & $0.25-4.87$ & 0.705 \\
\hline Unstable angina & 1.00 & $0.33-3.01$ & 0.995 \\
\hline \multicolumn{4}{|l|}{ ACC/AHA lesion characterization } \\
\hline Type A & 1.00 & - & - \\
\hline Type B1 & 0.29 & $0.08-1.06$ & 0.060 \\
\hline Type B2 & 0.64 & $0.22-1.81$ & 0.396 \\
\hline Type C & 0.50 & $0.13-1.93$ & 0.316 \\
\hline Pre-procedure \%DS & 1.03 & $0.99-1.08$ & 0.172 \\
\hline Post-procedure \%DS & 1.00 & $0.97-1.03$ & 0.792 \\
\hline \multicolumn{4}{|l|}{ Covariates interactions } \\
\hline Orsiro stent vs. age & - & - & 0.047 \\
\hline Orsiro stent vs. gender & - & - & 0.617 \\
\hline Orsiro stent vs. smoking & - & - & 0.806 \\
\hline Orsiro stent vs. diabetes & - & - & 0.491 \\
\hline Orsiro stent vs. unstable angina & - & - & 0.231 \\
\hline Orsiro stent vs. type A lesion & - & - & 0.585 \\
\hline Orsiro stent vs. type B1 lesion & - & - & 0.111 \\
\hline Orsiro stent vs. type B2 lesion & - & - & 0.997 \\
\hline Orsiro stent vs. type $C$ lesion & - & - & 0.200 \\
\hline Orsiro stent vs. pre-procedure \%DS & - & - & 0.916 \\
\hline $\begin{array}{l}\text { Orsiro stent vs. post-procedure \% } \\
\text { DS }\end{array}$ & - & - & 0.745 \\
\hline
\end{tabular}

Abbreviations: \%DS = percentage of diameter stenosis; $\mathrm{ACC}=$ American College of cardiology; $\mathrm{AHA}=$ American Heart Association; $\mathrm{CI}=$ confidence interval. unadjusted clinical outcomes for TLF did not reveal any statistically significant difference between the Magmaris or Orsiro groups, albeit after adjustment of all other covariates, the MVA showed a non-significant TLF reduction of $24 \%$ in hazard function for the Orsiro stent; and [2] neither Magmaris nor Orsiro presented any definite or probable ST case after 12 months.

The adoption of DES in percutaneous coronary intervention considerably decreased the in-stent restenosis rate in the majority of the coronary artery disease clinical scenarios [16-18]. In SPIRIT trial, the TLF rate between first- vs. second-generation DES over 12 months revealed an important reduction of events in the patients of the secondgeneration DES group [19]. Recently, Kandzari et al. in BIOFLOW V trial showed a TLF rate of $6.0 \%$ in the Orsiro group vs. $10.0 \%$ in the Xience group ( $p=0.030$ ) after 12 months [10]. In the current study, the Magmaris unadjusted TLF rate at 12 months was $6.0 \%$ with no relevant differences as compared to the Orsiro DES.

On the other hand, in the Absorb III trial, Absorb (a polymeric BRS) presented a TLF rate of $7.8 \%$ with a considerable difference $(p=$ 0.007 ) against the Xience group (6.1\%) over a year [20,21]. The Absorb data showed a higher ST rate than second-generation DES over time ( $1.5 \%$ vs. $0.7 \%$, respectively) [19]. Wykrzykowska et al. reported in the AIDA trial a $0.8 \%$ of late ST (Absorb group) and an accumulative definite or probable ST rate at 2 years of $3.5 \%$ vs. $0.9 \%$ in the DES group [4]. In contrast, neither Magmaris nor Orsiro unveiled any definite or probable ST cases in the present study. These differences may come from the difference in scaffold platform design and composition.

In the metallic DES era, the second-generation DES late ST rate decreased from $4.90 \%$ to $0.50 \%-0.70 \%[1,2,20]$. The Orsiro stent in the BIOFLOW V trial showed a lower, but not significant $(p=0.700)$, definite or probable ST rate of $0.48 \%$ compared to the Xience $(0.70 \%)$ at 12 months [10]. This lower rate can be partly attributed to the differences in strut thickness, abluminal biodegradable polymers, and newer drugs, all of which together resulted in an overall improvement of clinical outcomes in PCI patients $[10,19,20]$. In a sequence of preclinical porcine shunt models, Otsuka et al., Waksman et al. and Lipinski et al. explored the thrombogenecity of different device [22-24]. Otsuka et al. performed an acute thrombogenic test among second-generation metallic DES, and Xience presented better results compared to the other devices [22]; Waksman et al. showed a reduction of thrombus formation and better endothelization by Magmaris compared to Absorb and Xience [23]; and Lipinski et al. reported less acute thrombogenicity in Magmaris group compared with a Stainless Steel Platform group [24].

DAPT duration in BIOFLOW-II, BIOSOLVE-II and -III trials followed DAPT guideline recommendations of 6 months in stable CAD and 12 months acute coronary syndrome patients (ACS), still in use [25]. Through 6 months, all included patients in this pooled analysis had DAPT. From 6 to 12 months the DAPT duration was left to treating physician discretion who according to the clinical presentation (ACS vs nonACS) extended it through 12 months.

In many dedicated clinical trials, the use of invasive intracoronary imaging to guide PCI resulted in better clinical outcomes, mostly by reduction of acute and subacute ST [26,27]. In this pooled analysis which included trials that used Magmaris and Orsiro devices, the implantation technique did not require invasive imaging guidance, only standard angiography-based PCI technique. In the BIOSOLVE-II trial, Magmaris invasive imaging acquisition was performed after implantation of the device, with the purpose of follow-up its resorption process $[6,7,28]$.

Lastly, a Weibull proportional hazards regression analysis was performed, taking into account device type (i.e. Magmaris scaffold or Orsiro stent) and age (i.e. 55, 65 and 75 years) (Supplemental Fig. 1). The Magmaris group presented better outcomes in patients with 65 and 75 years and worst outcomes in younger patients (55 years) compared the Orsiro group that presented more TLF-free patients among the younger patients than in the older patients. These observations are hypothesis generating and warrant future randomized comparisons between the two devices. 


\section{Limitations}

First, this is a comparison between 1 randomized controlled trial and 2 single-arm registries. Second, the study compared Magmaris and a 2nd generation DES (Orsiro), which were tested in two different trials. As such, this analysis may be biased in regard to the selection of the patients. A sophisticated statistical analysis was performed to account for this, although some residual confounding factors cannot be excluded. Third, BIOSOLVE-II and -III trials treated less complex lesions. Forth, although we used the largest study datasets suitable for this comparison, this study may be underpowered for main effects. Finally, pooling data from different studies introduces an additional source of error that potentially affects the results/conclusions. One way to account for this is to include "study" in the analysis as a random effect. We have included sites within countries as random effects in our analyses because the BIOSOLVE and BIOFLOW studies themselves obtained data from different health care systems (countries) and different health care centers (sites).

\section{Conclusion}

At 12 months, there were no significant differences between the Magmaris and Orsiro groups for the unadjusted TLF assessment or the covariates multivariate analysis. Over a year, there were no definite or probable ST cases in the Magmaris or Orsiro groups. Lastly, the pertinence of the findings of the current analysis need to be seen in a bigger context, the results should be taken as hypothesis generating and thereafter confirmed with a larger cohort in a randomized controlled trial.

\section{Declaration of competing interest}

A.A. is a consultant to and has received research grants from Boston Scientific, Abbott Vascular, Elixir Medical and Reva Medical. R.T. reports receiving consultant fees and speakers honoraria from Abbott Vascular and Biotronik. P.A.L. reports grants from Biotronik, Boston Scientific, and Scitech. H. I. reports receiving lecture and consultancy fees from Boston Scientific. S. K. reports receiving honorarium from Biotronik. N.M. V M. has received research grants from Abbott Vascular, Boston Scientific, Medtronic, Claret Medical and PulseCath. S.V. is a consultant of Elixir and Neovasc. C.v B. reports institutional research grants from AstraZeneca, Biotronik, Boston Scientific, and Medtronic, and that he has been an unpaid consultant to device manufacturing companies, among them Biotronik. E.H.C. received institutional research grants and speaker fees from Abbott. W.W. reports grants from Abbott Vascular, Biotronik, and Terumo; and being a non-executive board member and shareholder of Argonauts Partners, Celyad. S.W. reports grants from Biotronik, Boston Scientific, Bracco Pharmaceutical, Edwards Lifesciences, Medtronic, Terumo Inc., and St Jude Medical. R.W. is a consultant of Abbott Vascular, Amgen, Biosensors International, Biotronik, Boston Scientific, Corindus, Lifetech Medical, Medtronic Vascular, Philips Volcano, and Symetis, acts for the speakers bureau of AstraZeneca, and receives grant support from Biosensors International, Biotronik, Boston Scientific, Edwards Lifesciences, and Abbott Vascular. M.H. reports study grants and lecture fees from Biotronik, Abbott Vascular, Cardiac dimensions, Medtronic, Volcano, and Lilly. All other authors have no relationships relevant to the contents of this article to disclose.

\section{Appendix A. Supplementary data}

Supplementary data to this article can be found online at https://doi. org/10.1016/j.ijcard.2019.11.003.

\section{References}

[1] R.A. Byrne, M. Joner, A. Kastrati, Stent thrombosis and restenosis: what have we learned and where are we going? The Andreas Grüntzig Lecture ESC 2014, Eur. Heart J. 36 (2015) 3320-3331, https://doi.org/10.1093/eurheartj/ehv511.
[2] L. Mauri, W.H. Hsieh, J.M. Massaro, K.K. Ho, R. D’Agostino, D.E. Cutlip, Stent thrombosis in randomized clinical trials of drug-eluting stents, N. Engl. J. Med. 356 (2007) 1020-1029.

[3] H.M. Garcia-Garcia, P.W. Serruys, C.M. Campos, et al., Assessing bioresorbable coronary devices: methods and parameters, JACC Cardiovasc. Imaging 7 (2014) 1130-1148, https://doi.org/10.1016/j.jcmg.2014.06.018.

[4] J.J. Wykrzykowska, R.P. Kraak, S.H. Hofma, AIDA Investigators, et al., Bioresorbable scaffolds versus metallic stents in routine PCI, N. Engl. J. Med. 376 (2017) 2319-2328, https://doi.org/10.1056/NEJMoa1614954.

[5] R.S. Nairooz, M. Saad, P. Sardar, Long-term outcomes of absorb bioresorbable vascular scaffold versus second generation DES in coronary artery disease: a metaanalysis, J. Am. Coll. Cardiol. 69 (2017) 1249.

[6] M. Haude, H. Ince, A. Abizaid, et al., Sustained safety and performance of the secondgeneration drug-eluting absorbable metal scaffold in patients with de novo coronary lesions: 12-month clinical results and angiographic findings of the BIOSOLVE-II first-in-man trial, Eur Heart J. 37 (2016) 2701-2709, https://doi.org/ 10.1093/eurheartj/ehw196.

[7] M. Haude, H. Ince, A. Abizaid, et al., Safety and performance of the secondgeneration drug-eluting absorbable metal scaffold in patients with de-novo coronary artery lesions (BIOSOLVE-II): 6 months results of a prospective, multicentre, non-randomised, first-in-man trial, Lancet. 387 (2016) 31-39, https://doi.org/10. 1016/S0140-6736(15)00447-X

[8] M. Haude, H. Ince, S. Kische, et al., Sustained safety and clinical performance of a drug-eluting absorbable metal scaffold up to 24 months: pooled outcomes of BIOSOLVE-II and BIOSOLVE-III, EuroIntervention. 13 (2017) 432-439, https://doi. org/10.4244/EIJ-D-17-00254.

[9] S. Windecker, M. Haude, F.J. Neumann, et al., Comparison of a novel biodegradable polymer sirolimus-eluting stent with a durable polymer everolimus-eluting stent: results of the randomized BIOFLOW-II trial, Circ Cardiovasc Interv. 8 (2015), e001441. https://doi.org/10.1161/CIRCINTERVENTIONS.114.001441.

[10] D.E. Kandzari, L. Mauri, J.J. Koolen, BIOFLOW V Investigators, et al., Ultrathin, bioresorbable polymer sirolimus-eluting stents versus thin, durable polymer everolimuseluting stents in patients undergoing coronary revascularisation (BIOFLOW V): a randomised trial, Lancet 390 (2017) 1843-1852, https://doi.org/10.1016/S01406736(17)32249-3.

[11] D.E. Cutlip, S. Windecker, R. Mehran, Academic Research Consortium, et al., Clinical end points in coronary stent trials: a case for standardized definitions, Circulation. 115 (2007) 2344-2351, https://doi.org/10.1161/CIRCULATIONAHA.106.685313.

[12] K. Thygesen, J.S. Alpert, A.S. Jaffe, Writing Group on the Joint ESC/ACCF/AHA/WHF Task Force for the Universal Definition of Myocardial Infarction, ESC Committee for Practice Guidelines (CPG), et al., Third universal definition of myocardial infarction, Eur Heart J. 33 (2012) 2551-2567, https://doi.org/10.1093/eurheartj/ehs184.

[13] I.D. Moussa, LW. Klein, B. Shah, et al, Consideration of a new definition of clinically relevant myocardial infarction after coronary revascularization: an expert consensus document from the Society for Cardiovascular Angiography and Interventions (SCAI), J. Am. Coll. Cardiol. 62 (2013) 1563-1570.

[14] J.P. Klein, M.L. Moeschberger, Survival Analysis: Techniques for Censored and Truncated Data, 2nd ed. Springer, New York, 20051.

[15] Z. Zhang, Parametric regression model for survival data: Weibull regression model as an example, Ann Transl Med. 4 (2016) 484, https://doi.org/10.21037/atm.2016. 08.45 .

[16] U. Sigwart, J. Puel, V. Mirkovitch, F. Joffre, L. Kappenberger, Intravascular stents to prevent occlusion and restenosis after transluminal angioplasty, N. Engl. J. Med. 316 (1987) 701-706.

[17] A.V. Finn, M. Joner, G. Nakazawa, et al., Pathological correlates of late drug-eluting stent thrombosis: strut coverage as a marker of endothelialization, Circulation. 115 (2007) 2435-2441.

[18] M. Joner, A.V. Finn, A. Farb, et al., Pathology of drug-eluting stents in humans: delayed healing and late thrombotic risk, J A Col Cardiol. 48 (2006) 193-202.

[19] S.G. Ellis, D.J. Kereiakes, D.C. Metzger, ABSORB III Investigators, et al., Everolimuseluting bioresorbable scaffolds for coronary artery disease, N Engl J Med. 373 (2015) 1905-1915, https://doi.org/10.1056/NEJMoa1509038(Epub 2015 Oct 12. PubMed PMID: 26457558).

[20] G.W. Stone, A. Rizvi, K. Sudhir, et al, Randomized comparison of everolimus- and paclitaxel-eluting stents. 2-year follow-up from the SPIRIT (clinical evaluation of the XIENCE V Everolimus eluting coronary stent system) IV trial, J. Am. Coll. Cardiol. 58 (2011) 19-25.

[21] J. Iqbal, Y. Onuma, J. Ormiston, A. Abizaid, R. Waksman, P. Serruys, Bioresorbable scaffolds: rationale, current status, challenges, and future, Eur. Heart J. 35 (2014) 765-776.

[22] F. Otsuka, Q Cheng, K. Yahagi, et al, Acute thrombogenicity of a durable polymer everolimus-eluting stent relative to contemporary drug-eluting stents with biodegradable polymer coatings assessed ex vivo in a swine shunt model, JACC Cardiovasc Interv. 8 (2015) 1248-1260, https://doi.org/10.1016/j.jcin.2015.03.029.

[23] R. Waksman, M.J. Lipinski, E. Acampado, et al., Comparison of acute thrombogenicity for metallic and polymeric bioabsorbable scaffolds: Magmaris versus absorb in a porcine arteriovenous shunt model, Circ Cardiovasc Interv. 10 (2017) https://doi. org/10.1161/CIRCINTERVENTIONS.116.004762pii: e004762.

[24] M.J. Lipinski, E. Acampado, Q. Cheng, et al., Comparison of acute thrombogenicity for magnesium versus stainless steel stents in a porcine arteriovenous shunt model, EuroIntervention (2018) https://doi.org/10.4244/EIJ-D-17-00958pii: EIJ-D-1700958.

[25] M. Valgimigli, H. Bueno, R.A. Byrne, J.P. Collet, F. Costa, A. Jeppsson, P. Jüni, A. Kastrati, P. Kolh, L. Mauri, G. Montalescot, F.J. Neumann, M. Petricevic, M. Roffi, P.G. Steg, S. Windecker, J.L. Zamorano, G.N. Levine, ESC Scientific Document Group, 2017 ESC focused update on dual antiplatelet therapy in coronary artery 
disease developed in collaboration with EACTS, Eur. J. Cardiothorac. Surg. 53 (1) (2018 Jan 1) 34-78, https://doi.org/10.1093/ejcts/ezx334.

[26] F. Prati, T. Kodama, E. Romagnoli, L. Gatto, L. Di Vito, V. Ramazzotti, A. Chisari, V. Marco, A. Cremonesi, G. Parodi, M. Albertucci, F. Alfonso, Suboptimal stent deployment is associated with subacute stent thrombosis: optical coherence tomography insights from a multicenter matched study. From the CLI Foundation investigators: the CLITHRO study, Am. Heart J. 169 (2015) 249-256.

[27] P. Garg, BZ Galper, D.J. Cohen, R.W. Yeh, L. Mauri, Balancing the risks of bleeding and stent thrombosis: a decision analytic model to compare durations of dual antiplatelet therapy after drug-eluting stents, Am Heart J 169 (2015) 222-233(e5).
[28] H.M. Garcia-Garcia, M. Haude, K. Kuku, A. Hideo-Kajita, H. Ince, A. Abizaid, R. Tölg P.A. Lemos, C. von Birgelen, E.H. Christiansen, W. Wijns, J. Escaned, J. Dijkstra, R. Waksman, In vivo serial invasive imaging of the second-generation drug-eluting absorbable metal scaffold (Magmaris - DREAMS 2G) in de novo coronary lesions: insights from the BIOSOLVE-II First-In-Man Trial, Int. J. Cardiol. 255 (2018 Mar 15) 22-28, https://doi.org/10.1016/j.ijcard.2017.12.053. 